\title{
Multiport Network Model of Double-stub Loaded Microstrip Ring Antenna for Tri-band Operation
}

\author{
Suman PRADHAN, Bhaskar GUPTA \\ Dept. of ETCE, Jadavpur University, Kolkata 700032, India \\ sumanpradhan.kut2@gmail.com,gupta_bh@yahoo.com \\ Submitted November 29, 2018 / Accepted May 1, 2019
}

\begin{abstract}
A microstrip ring antenna has a single broadside fundamental radiating mode. In this paper one of the arms of the ring has been loaded with two stubs, so that the perturbation in the fields results in broadside radiation in the next two higher order modes. This results in three broadside radiating modes. Gap-coupled excitation is chosen to achieve impedance matching in all the three frequency bands. Linearly polarized radiation with gain of $2.88 \mathrm{~dB}, 4.67 \mathrm{~dB}$ and $6.07 \mathrm{~dB}$ and half-power beamwidth of $89.6^{\circ}, 76.3^{\circ}$ and $79^{\circ}$ in the $\varphi=90^{\circ}$ plane has been achieved at the center frequencies of $0.9526 \mathrm{GHz}$, $1.833 \mathrm{GHz}$ and $2.468 \mathrm{GHz}$ respectively. This structure has been analyzed using multiport network modeling. The modeling is vindicated by experimental results.
\end{abstract}

\section{Keywords}

Broadside radiation, gap-coupling, microstrip ring antenna, multiport network model

\section{Introduction}

Multi-band antennas are indispensable for modern wireless communication systems. Multi-band operation can be achieved by introducing additional resonances by addition of slots or stubs [1], [2] or by perturbing the structure to change the radiation characteristics of the higher order modes [3]. Microstrip ring antennas have resonances when the path length of the ring is in multiples of guided wavelength $\left(\lambda_{\mathrm{g}}\right)$ [4]. At the first resonance, each edge is quarter wavelength long and the structure is smaller compared to a microstrip patch antenna. Direct coaxial feeding is impractical for ring antennas as they have very high values of input impedance [5]. Proximity coupling [6], [7] or gapcoupling [8] are the ways to feed a ring antenna.

As the ring antenna has one broadside radiating mode, multiple rings have been placed concentrically to achieve multiband operation [9], [10]. Circular polarization has been achieved by placing cross-strips inside the ring [11] and by proximity coupling the antenna to a curved microstrip line [12]. Quarter wavelength long single and double open circuit stubs have been placed outside the ring along with a shorting post in [13] which produce additional reso- nances in the vicinity of the fundamental mode and give triple band and quad band operation respectively. A single stub has been incorporated inside the ring antenna in [14] which alters the current distribution so that the second mode also becomes broadside radiating and a dual-band antenna is realized.

Multiport network model (MNM) was proposed in [15]. It is basically an extension of cavity model. Cavity model is suited for analyzing those geometries for which the Green's function is known. But complex structures are required for many applications. For analyzing these types of structures, MNM is used if the geometry can be expressed as combination of regular structures for which Green's functions are available. Segmentation or desegmentation [16], [17] method can be used accordingly. MNM has been applied in analyzing circularly polarized microstrip ring antenna in [18]. Gap-coupling has been modeled using MNM [19]. MNM analysis has been done for a single stub and double stub loaded at the outer periphery of the microstrip ring antennas [13]. Single stub placed at the inner periphery of a microstrip ring antenna has been analyzed for proximity coupled feed [20].

In this paper, we introduce two stubs on the inside periphery of the gap coupled ring such that not only the second mode, the third mode also produces broadside radiation efficiently thus giving a tri-band antenna. Although triple band operation in ring antenna has been previously reported in [13], placement of stub outside the ring makes the size of the antenna $\left(\sim 0.32 \lambda_{\mathrm{g}} \times 0.5 \lambda_{\mathrm{g}}\right)$ larger compared to a simple ring antenna. As the stubs in the proposed design are located inside the ring, the antenna size $\left(\sim 0.36 \lambda_{\mathrm{g}} \times 0.32 \lambda_{\mathrm{g}}\right)$ is comparable to a ring antenna. MNM of the structure has been formed using which parametric studies are performed. Based on these studies the final design has been obtained. Upon fabrication the modeling is verified by experimental results.

\section{Double-stub Loaded Microstrip Ring Antenna}

Two open circuited stubs are placed symmetrically on the inner periphery of a microstrip rectangular ring antenna. Gap-coupled excitation is chosen as direct coaxial feeding 


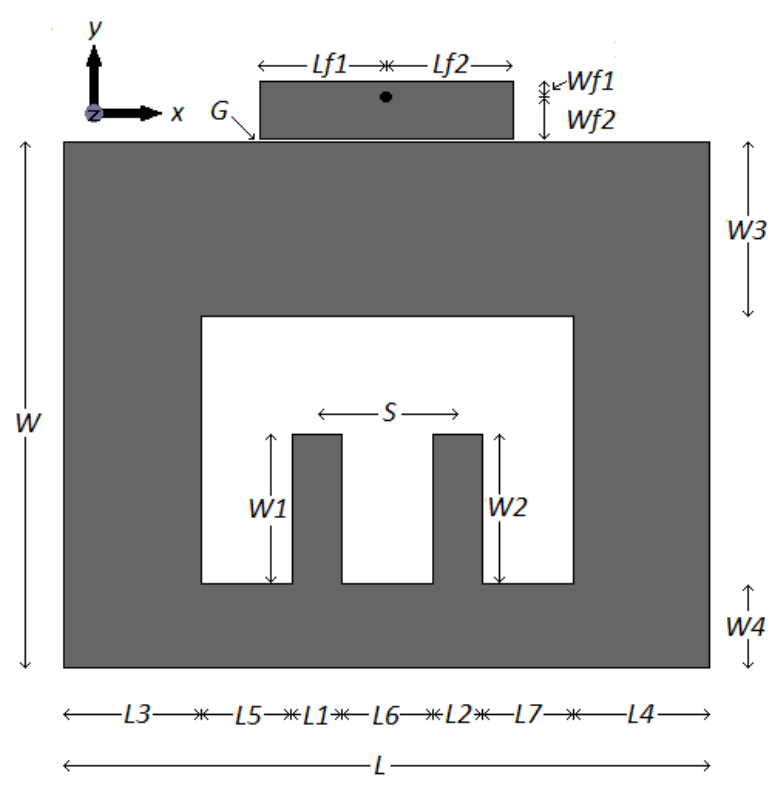

Fig. 1. Geometry of the antenna.

on the ring and produces very high magnitude of input impedance at the resonant frequencies which makes the antenna extremely difficult to match. The separation between the stubs along with their dimensions determines the nature of radiation pattern and the resonant frequencies. The ratio of the resonant frequencies can also be varied by introducing asymmetry in the ring.

The antenna is made on an ARLON AD 250 substrate of $\varepsilon_{\mathrm{r}}=2.5$, thickness 125 mils and loss tangent 0.0018 at $10 \mathrm{GHz}$. The dimensions are chosen such that the resonant frequencies lie in the GSM 900, GSM 1800 and $2.45 \mathrm{GHz}$ Wi-fi band. The structure of the antenna is shown in Fig. 1. MNM analysis for it is performed in the next section.

\section{Analysis Using MNM}

The first step in MNM is to determine the position of the magnetic walls of the cavity. For this the physical di-

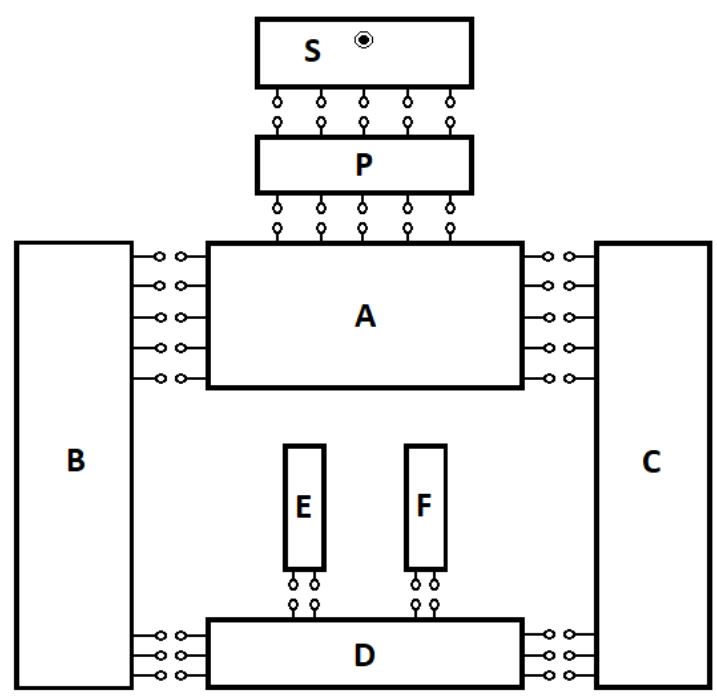

Fig. 2. Segmentation of the structure. mensions have to be extended to account for the fringing fields. The formulas for length extension can be found in [21].

In the next step the structure is broken up into multiple segments for which the characteristics are well known. The antenna has been decomposed into seven rectangular segments along with a gap-coupling network as shown in Fig. 2.

Ports have been assigned along the edges of the segments in spacing of $\lambda_{\mathrm{g}} / 20$. Also one port has been assigned to the feed point. Only some of the interconnecting ports have been shown in the figure. The Green's function for a rectangular segment which relates the E-field at a point $(x, y)$ to unit current density at a point $\left(x_{0}, y_{0}\right)$ is given in a modal summation form by [22]

$$
\begin{aligned}
& G\left(x, y ; x_{\mathrm{o}}, y_{\mathrm{o}}\right) \\
& =\frac{\mathrm{j} \omega \mu_{\mathrm{o}}}{a b} \sum_{m=0}^{\infty} \sum_{n=0}^{\infty} \frac{\cos \left(\lambda_{\mathrm{x}} x_{\mathrm{o}}\right) \cos \left(\lambda_{\mathrm{y}} y_{\mathrm{o}}\right) \cos \left(\lambda_{\mathrm{x}} x\right) \cos \left(\lambda_{\mathrm{y}} y\right)}{k^{2}-\lambda_{\mathrm{x}}^{2}-\lambda_{\mathrm{y}}^{2}} \sigma_{m} \sigma_{n}
\end{aligned}
$$

where $\lambda_{\mathrm{x}}=m \pi / a, m=0,1,2,3, \ldots, \lambda_{\mathrm{y}}=n \pi / b, \quad n=0,1,2,3, \ldots$, $k^{2}=k_{\mathrm{o}}^{2} \varepsilon_{\mathrm{r}}\left(1-\mathrm{j} \delta_{\text {eff }}\right), k_{\mathrm{o}}^{2}=\omega^{2} \mu_{\mathrm{o}} \varepsilon_{\mathrm{o}}, \delta_{\text {eff }}$ is effective loss tangent of the structure $\delta_{\text {eff }}=\delta_{\mathrm{c}}+\delta_{\mathrm{d}}+\delta_{\mathrm{r}}, \delta_{\mathrm{d}}$ is loss tangent of the dielectric, $\delta_{\mathrm{c}}=1 /\left(h \sqrt{\pi f \mu_{\mathrm{o}} \sigma}\right), \delta_{\mathrm{r}}=P_{\mathrm{r}} /\left(\omega S_{\mathrm{T}}\right), P_{\mathrm{r}}$ is power radiated from the antenna, $S_{\mathrm{T}}$ is stored energy in the dielectric, and

$$
\begin{gathered}
\sigma_{m}= \begin{cases}1 & \text { for } m=0 \\
2 & \text { for } m \neq 0\end{cases} \\
\sigma_{n}= \begin{cases}1 & \text { for } n=0 \\
2 & \text { for } n \neq 0\end{cases}
\end{gathered}
$$

and $a$ and $b$ are the length and width of the rectangular segment, respectively. Rest of the symbols have their usual meanings. Using this Green's function, one can obtain the impedance matrix of the segment which relates the voltages and currents of each port of the segment. For this matrix, a typical element for both ports oriented along y-direction is given by

$$
\begin{aligned}
& Z_{i j}=\frac{\mathrm{j} \omega \mu_{\mathrm{o}} h}{a b} \\
& \sum_{m=0}^{\infty} \sum_{n=0}^{\infty} \frac{\sigma_{m} \sigma_{n}}{\lambda_{\mathrm{x}}^{2}+\lambda_{\mathrm{y}}^{2}-k^{2}} \cos \left(\lambda_{\mathrm{x}} x_{i}\right) \cos \left(\lambda_{\mathrm{y}} y_{i}\right) \operatorname{sinc}\left(\frac{\lambda_{\mathrm{y}} W_{i}}{2}\right) \\
& \cos \left(\lambda_{\mathrm{x}} x_{j}\right) \cos \left(\lambda_{\mathrm{y}} y_{j}\right) \operatorname{sinc}\left(\frac{\lambda_{\mathrm{y}} W_{j}}{2}\right)
\end{aligned}
$$

where $h$ is the height of the substrate and $W_{i}$ and $W_{j}$ are the width of the ports oriented in the y-direction. Once the Zmatrix of each segment is known, they can be added one by one using segmentation technique to find the overall $\mathrm{Z}$ matrix of the antenna structure.

If $p$ denotes the unconnected ports of the two segments $\mathrm{A}$ and $\mathrm{B}$ which are to be combined and $q$ and $r$ denote the connected ports of the two segments respectively, 


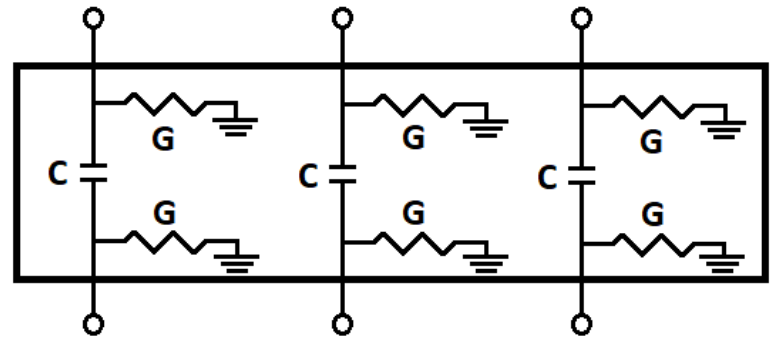

Fig. 3. Gap-coupling network 'P'.

then according to the segmentation technique the combined Z-matrix is given by [23]

$$
\left[Z_{A B}\right]=\left[Z_{p p}\right]+\left[Z_{p q}-Z_{p r}\right]\left[Z_{q q}+Z_{r r}\right]^{-1}\left[Z_{r p}-Z_{q p}\right]
$$

For obtaining the overall Z-matrix, the Z-matrix of the gap-coupling network ' $\mathrm{P}$ ' is needed. The gap has been modeled as a $\pi$ network which has the radiation conductance associated with ports facing each other in shunt and a series capacitance. The radiation conductance associated with each port located on that portion of the edge of segment ' $A$ ' that is gap coupled can be found out by calculating the radiation from that port. Although the final field distribution is not known at this stage, still the radiation conductance can be found out as it depends on the length of the port and doesn't depend on the value of the field as it is considered constant along the length of each port. The series gap capacitance can be found out from [24]. The gap coupling network is shown in Fig. 3.

Initially $P_{\mathrm{r}}$ is unknown and $\delta_{\mathrm{r}}$ is taken as zero. All the $\mathrm{Z}$-matrices are combined to get the Z-matrix of the antenna structure which contains the open-circuited ports along the edges and the feed point. From the Z-matrix the field variation along the edges is obtained from which the radiation from the antenna can be calculated.

The radiated fields from the microstrip antenna are given by

$$
\begin{aligned}
& E_{\theta}=\mathrm{j} \omega \eta_{\mathrm{o}}\left(F_{\mathrm{x}} \sin \phi-F_{\mathrm{y}} \cos \phi\right) \\
& E_{\phi}=\mathrm{j} \omega \eta_{\mathrm{o}}\left(F_{\mathrm{x}} \cos \theta \cos \phi+F_{\mathrm{y}} \cos \theta \sin \phi\right) \text {. } \\
& F_{\mathrm{x}}=\frac{\varepsilon_{\mathrm{o}}}{4 \pi} \cdot \frac{\exp \left(-\mathrm{j} k_{\mathrm{o}} r\right)}{r} \cdot \int_{X_{\mathrm{o}}-\frac{W_{\mathrm{x}}}{2}}^{X_{Y_{\mathrm{o}}}} \int_{-\frac{h}{2}}^{X_{\mathrm{X}}} \int_{Y_{\mathrm{x}}}^{\frac{h}{2}} M_{\mathrm{x}} \exp \left(\mathrm{j} k_{\mathrm{o}}(x \sin \theta \cos \phi+y \sin \theta \sin \phi+z \cos \theta)\right) \mathrm{d} x \mathrm{~d} y \mathrm{~d} z, \\
& \Rightarrow F_{\mathrm{x}}=\frac{\varepsilon_{\mathrm{o}}}{4 \pi} \cdot \frac{\exp \left(-\mathrm{j} k_{\mathrm{o}} r\right)}{r} \cdot M_{\mathrm{x}} \cdot \exp \left(\mathrm{j} k_{\mathrm{o}}\left(X_{\mathrm{o}} \sin \theta \cos \phi+Y_{\mathrm{o}} \sin \theta \sin \phi\right)\right) \cdot W_{\mathrm{x}} \cdot \operatorname{sinc}\left(k_{\mathrm{o}} \sin \theta \cos \phi \cdot W_{\mathrm{x}} / 2\right) \cdot h \cdot \operatorname{sinc}\left(k_{\mathrm{o}} \cos \theta \cdot h / 2\right), \\
& F_{\mathrm{y}}=\frac{\varepsilon_{\mathrm{o}}}{4 \pi} \cdot \frac{\exp \left(-\mathrm{j} k_{\mathrm{o}} r\right)}{r} \cdot \int_{X_{\mathrm{o}}}^{X_{\mathrm{o}}} \int_{Y_{\mathrm{o}}-\frac{W_{\mathrm{y}}}{2}-\frac{W^{2}}{2}}^{Y_{\mathrm{o}}+\frac{W_{\mathrm{y}}}{2}} \int_{\frac{h}{2}}^{\frac{h}{2}} M_{\mathrm{y}} \exp \left(\mathrm{j} k_{\mathrm{o}}(x \sin \theta \cos \phi+y \sin \theta \sin \phi+z \cos \theta)\right) \mathrm{d} x \mathrm{~d} y \mathrm{~d} z, \\
& \Rightarrow F_{\mathrm{y}}=\frac{\varepsilon_{\mathrm{o}}}{4 \pi} \cdot \frac{\exp \left(-\mathrm{j} k_{\mathrm{o}} r\right)}{r} \cdot M_{\mathrm{y}} \cdot \exp \left(\mathrm{j} k_{\mathrm{o}}\left(X_{\mathrm{o}} \sin \theta \cos \phi+Y_{\mathrm{o}} \sin \theta \sin \phi\right)\right) \cdot W_{\mathrm{y}} \cdot \operatorname{sinc}\left(k_{\mathrm{o}} \sin \theta \sin \phi \cdot W_{\mathrm{y}} / 2\right) \cdot h \cdot \operatorname{sinc}\left(k_{\mathrm{o}} \cos \theta \cdot h / 2\right) \cdot \\
& P_{\mathrm{c}}=\frac{\omega S_{\mathrm{T}}}{h \sqrt{\pi f \mu_{\mathrm{o}} \sigma}} \\
& P_{\mathrm{d}}=\omega \delta_{\mathrm{d}} S_{\mathrm{T}} .
\end{aligned}
$$

For an $\mathrm{x}$-directed edge having center at $\left(X_{\mathrm{o}}, Y_{\mathrm{o}}\right)$ and width $W_{\mathrm{x}}, F_{\mathrm{x}}$ is given by (6), (7) (see below) where $\mathbf{M}_{\mathrm{x}}$ is the $\mathrm{x}$-directed magnetic current density which is given by

$$
\mathbf{M}_{\mathrm{x}}=-2 \hat{\mathbf{n}} \times \mathbf{E}_{\mathrm{z}} .
$$

$\mathbf{E}_{\mathrm{z}}$ is the internal field in the cavity which is obtained from the Z-matrix of the antenna. For an y-directed edge having center at $\left(X_{\mathrm{o}}, Y_{\mathrm{o}}\right)$ and width $W_{\mathrm{y}}, F_{\mathrm{y}}$ is given by (9), (10) (see below) where $\mathbf{M}_{\mathrm{y}}$ is the $\mathrm{y}$-directed magnetic current density which is given by

$$
\mathbf{M}_{\mathrm{y}}=-2 \hat{\mathbf{n}} \times \mathbf{E}_{\mathrm{z}} .
$$

$\mathbf{E}_{\mathrm{z}}$ is the internal field in the cavity which is obtained from the Z-matrix of the antenna. Once the radiation is calculated from all the edges, the radiated power is calculated from the following expression.

$$
P_{\mathrm{r}}=\frac{1}{2 \eta_{\mathrm{o}}} \int_{0}^{\pi / 2} \int_{0}^{2 \pi}\left(\left|E_{\theta}\right|^{2}+\left|E_{\phi}\right|^{2}\right) r^{2} \sin \theta \mathrm{d} \theta \mathrm{d} \phi .
$$

From the radiation pattern the radiation loss tangent $\delta_{\mathrm{r}}$ can be calculated if the stored energy $\left(S_{\mathrm{T}}\right)$ is known. It is given by

$$
S_{\mathrm{T}}=\frac{\varepsilon_{\mathrm{o}} \varepsilon_{\mathrm{r}}}{4} \iiint\left|E_{\mathrm{z}}\right|^{2} \mathrm{~d} v+\frac{\mu_{\mathrm{o}}}{4} \iiint\left(\left|H_{\mathrm{x}}\right|^{2}+\left|H_{\mathrm{y}}\right|^{2}\right) \mathrm{d} v .
$$

For calculating this stored energy the final field distribution in the whole structure needs to be known. The initial cavity model analysis of each rectangular segment considered all the edges to be magnetic walls. But due to interconnections between the segments at some part of the edges, the initial field distribution will be modified. For that the currents at the connected edges needs to be known and can be found out according to the procedure outlined in [25].

The power lost in the conductor and the power dissipated in the dielectric are given by 
Finally, this loss tangent $\left(\delta_{\mathrm{r}}\right)$ is used to modify the effective loss tangent $\left(\delta_{\text {eff }}\right)$. The segmentation procedure is again performed to get the overall Z-matrix of the structure from which the input impedance is obtained. The radiated power, power lost in the dielectric and the power lost in the conductor along with the stored energy are again calculated from which the efficiency and antenna gain can be obtained.

As cavity model analysis involves a modal summation, finite number of modes are to be taken into consideration. The number of modes to be taken is determined by observing the variation of resonant frequencies with the number of modes. A square ring with the dimensions $L=$ $60 \mathrm{~mm}, L 1=6 \mathrm{~mm}, L 2=6 \mathrm{~mm}, L 3=10 \mathrm{~mm}, L 4=10 \mathrm{~mm}$, $L 5=11 \mathrm{~mm}, L 6=6 \mathrm{~mm}, L 7=11 \mathrm{~mm}, L \mathrm{fl}=15 \mathrm{~mm}, L \mathrm{f} 2=$ $15 \mathrm{~mm}, W=60 \mathrm{~mm}, W 1=10 \mathrm{~mm}, W 2=10 \mathrm{~mm}, W 3=$ $10 \mathrm{~mm}, W 4=10 \mathrm{~mm}, W \mathrm{f} 1=2 \mathrm{~mm}, W f 2=5 \mathrm{~mm}$ and $G=$ $0.4 \mathrm{~mm}$ is considered. Figure 4 shows the variation of three resonant frequencies with varying $m$ when $n$ is taken as 5 .

Figure 5 shows the variation of three resonant frequencies with varying $n$ when $m$ is taken as 5 .

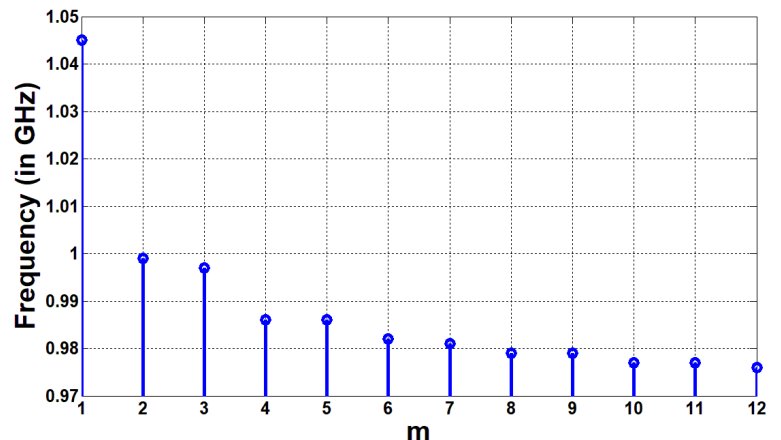

(a)

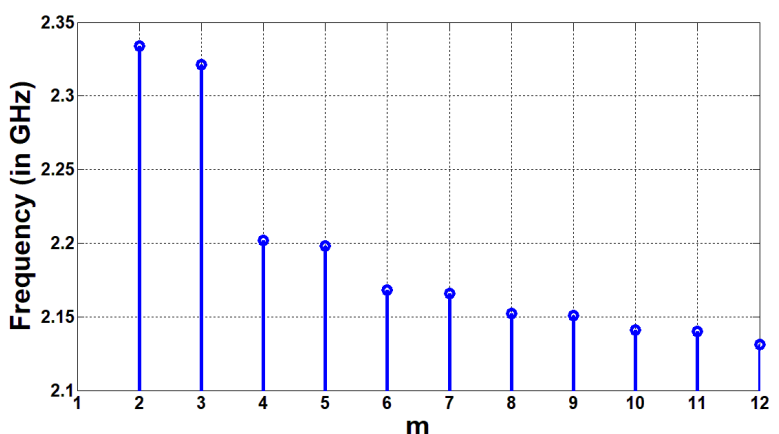

(b)

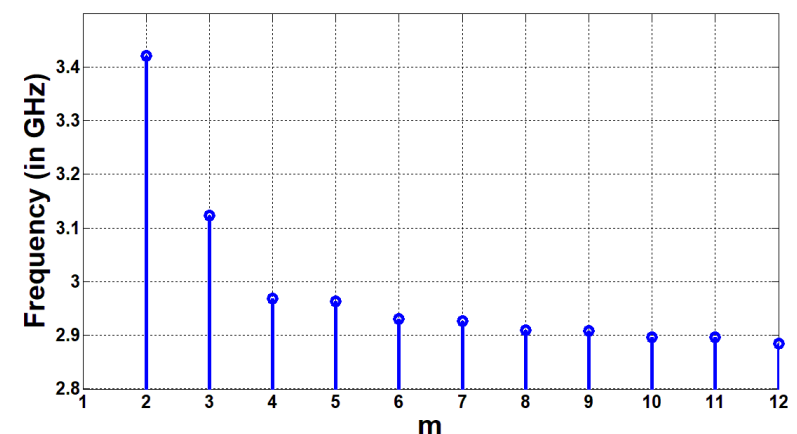

(c)

Fig. 4. Variation of (a) $f 1$, (b) $f 2$ and (c) $f 3$ with $m$ with $n=5$.

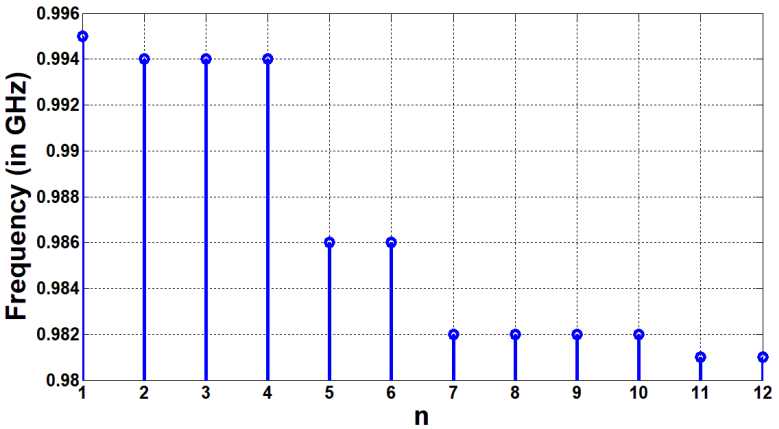

(a)

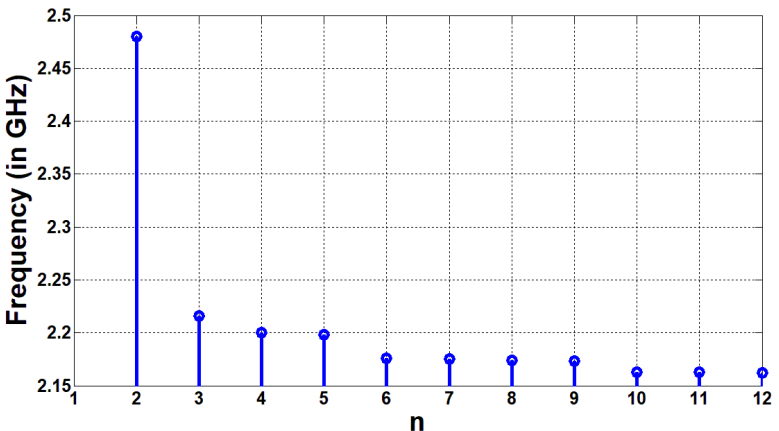

(b)

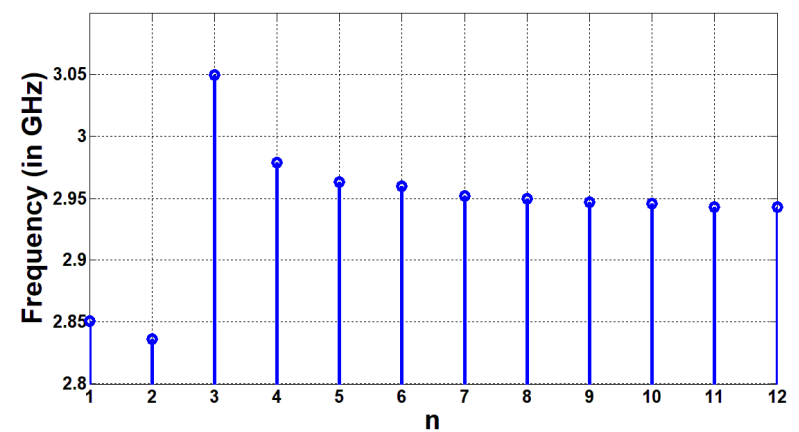

(c)

Fig. 5. Variation of (a) $f 1$, (b) $f 2$ and (c) $f 3$ with $n$ with $m=5$.

It is observed that the variation of the resonant frequencies is much less than $1 \%$ when $m$ or $n$ became 10 . So both $m$ and $n$ are taken as 10 in the analysis.

Next some parametric studies are done using MNM where the resonant frequencies are observed. First the lengths of the stubs are varied keeping all other parameters constant.

It can be observed in Tab. 1 that although $f 2 / f 1$ remains almost constant with the increasing stub length whereas $f 3 / f 1$ increases. Next the widths of the stubs are varied keeping all other parameters constant.

It can be observed in Tab. 2 that both $f 2 / f 1$ and $f 3 / f 1$ decrease with the increasing stub width. Next the separation between the stubs is varied keeping the other parameters constant.

It can be observed in Tab. 3 that $f 1$ remains constant as the perimeter of the ring does not change with increase in stub separation, but both $f 2$ and $f 3$ increase. This results in increase of both $f 2 / f 1$ and $f 3 / f 1$ with increase in the separation of the two stubs. 


\begin{tabular}{|c|c|c|c|c|c|}
\hline $\begin{array}{c}\boldsymbol{L 1}=\boldsymbol{L 2} \\
(\mathbf{m m})\end{array}$ & $\begin{array}{c}\boldsymbol{f 1} \\
(\mathbf{G H z})\end{array}$ & $\begin{array}{c}\boldsymbol{f} 2 \\
(\mathbf{G H z})\end{array}$ & $\begin{array}{c}\boldsymbol{f 3} \\
(\mathbf{G H z})\end{array}$ & $\boldsymbol{f} \mathbf{2} / \boldsymbol{f 1}$ & $\boldsymbol{f 3} / \mathbf{f 1}$ \\
\hline 2 & 0.997 & 2.174 & 2.950 & 2.18 & 2.958 \\
\hline 4 & 0.986 & 2.148 & 2.918 & 2.178 & 2.959 \\
\hline 6 & 0.975 & 2.127 & 2.894 & 2.181 & 2.968 \\
\hline 8 & 0.966 & 2.108 & 2.880 & 2.182 & 2.981 \\
\hline 10 & 0.956 & 2.090 & 2.870 & 2.186 & 3.002 \\
\hline
\end{tabular}

Tab. 1. Comparison of resonant frequency with varying stub length, $L=W=60 \mathrm{~mm}, L 3=L 4=W 3=W 4=10 \mathrm{~mm}$, $W 1=W 2=10 \mathrm{~mm}, \quad S=12 \mathrm{~mm}, \quad W \mathrm{fl} 1=2 \mathrm{~mm}$ $W \mathrm{f} 2=5 \mathrm{~mm}, L \mathrm{f} 1=L \mathrm{f} 2=15 \mathrm{~mm}$ and $G=0.4 \mathrm{~mm}$.

\begin{tabular}{|c|c|c|c|c|c|}
\hline $\begin{array}{c}W \mathbf{1}=\boldsymbol{W} \mathbf{2} \\
(\mathbf{m m})\end{array}$ & $\begin{array}{c}\boldsymbol{f} \mathbf{1} \\
(\mathbf{G H z})\end{array}$ & $\begin{array}{c}\mathbf{f} 2 \\
(\mathbf{G H z})\end{array}$ & $\begin{array}{c}\boldsymbol{f 3} \\
(\mathbf{G H z})\end{array}$ & $\boldsymbol{f 2} / \boldsymbol{f 1}$ & $\boldsymbol{f 3} / \boldsymbol{f 1}$ \\
\hline 2 & 1.019 & 2.229 & 3.046 & 2.187 & 2.989 \\
\hline 6 & 1.001 & 2.190 & 2.989 & 2.187 & 2.986 \\
\hline 10 & 0.980 & 2.136 & 2.905 & 2.179 & 2.964 \\
\hline 14 & 0.959 & 2.061 & 2.790 & 2.149 & 2.909 \\
\hline 18 & 0.936 & 1.967 & 2.661 & 2.101 & 2.843 \\
\hline
\end{tabular}

Tab. 2. Comparison of resonant frequency with varying stub width, $L=W=60 \mathrm{~mm}, L 3=L 4=W 3=W 4=10 \mathrm{~mm}$, $L 1=L 2=5 \mathrm{~mm}, \quad S=12 \mathrm{~mm}, \quad W \mathrm{f} 1=2 \mathrm{~mm}, \quad W \mathrm{f} 2=$ $5 \mathrm{~mm}, L \mathrm{f} 1=L \mathrm{f} 2=15 \mathrm{~mm}$ and $G=0.4 \mathrm{~mm}$.

\begin{tabular}{|c|c|c|c|c|c|}
\hline $\begin{array}{c}\boldsymbol{S} \\
(\mathbf{m m})\end{array}$ & $\begin{array}{c}\boldsymbol{f} \mathbf{1} \\
(\mathbf{G H z})\end{array}$ & $\begin{array}{c}\boldsymbol{f} \mathbf{2} \\
(\mathbf{G H z})\end{array}$ & $\begin{array}{c}\mathbf{f 3} \\
(\mathbf{G H z})\end{array}$ & $\boldsymbol{f} \mathbf{2} / \boldsymbol{f} \mathbf{1}$ & $\boldsymbol{f} \mathbf{3} / \mathbf{f} \mathbf{1}$ \\
\hline 6 & 0.984 & 2.122 & 2.858 & 2.156 & 2.904 \\
\hline 8 & 0.985 & 2.131 & 2.880 & 2.163 & 2.924 \\
\hline 10 & 0.985 & 2.140 & 2.899 & 2.172 & 2.943 \\
\hline 12 & 0.986 & 2.148 & 2.918 & 2.178 & 2.959 \\
\hline 14 & 0.986 & 2.156 & 2.936 & 2.186 & 2.977 \\
\hline
\end{tabular}

Tab. 3. Comparison of resonant frequency with varying stub separation, $L=W=60 \mathrm{~mm}, \quad L 3=L 4=W 3=W 4=$ $10 \mathrm{~mm}, L 1=L 2=4 \mathrm{~mm}, W 1=W 2=10 \mathrm{~mm}, W \mathrm{f} 1=$ $2 \mathrm{~mm}, \quad W \mathrm{f} 2=5 \mathrm{~mm}, \quad L \mathrm{f} 1=L \mathrm{f} 2=15 \mathrm{~mm} \quad$ and $G=0.4 \mathrm{~mm}$.

All the studies till now have been done on a square ring. Next the length of the ring is increased and the width decreased in such a way as to keep the perimeter of the ring constant and the other parameters have been kept fixed.

It can be observed in Tab. 4 that $f 1$ increases as the ring is made more flat, $f 2$ and $f 3$ decrease which results in decrease in both $f 2 / f 1$ and $f 3 / f 1$. All the parametric studies which have been done till now show that both $f 2$ and $f 3$ increase or decrease simultaneously. Next the ring is made asymmetric by increasing $W 3$ and decreasing $W 4$ by the same amount keeping all other parameters constant.

It can be observed in Tab. 5 that although $f 2$ decreases with increasing asymmetry, $f 3$ increases. Also it can be seen that initially $f 1$ remains constant but increases rapidly after a certain point. Therefore $f 2 / f 1$ decreases but there is an initial increase in $f 3 / f 1$ which later decreases. Next the effect of varying the stub length in an asymmetric ring is observed.

It can be observed in Tab. 6 that the effect of varying stub length is the same for both the symmetric and asymmetric rings. The other parametric studies which are performed for the symmetric ring are done on the asymmetric ring also and the same trend is noticed. Based on the initial parametric studies, the final design with the resonant frequencies in the desired frequency bands is obtained using simulation.

\begin{tabular}{|c|c|c|c|c|c|c|}
\hline $\begin{array}{c}\boldsymbol{L} \\
(\mathbf{m m})\end{array}$ & $\begin{array}{c}\boldsymbol{W} \\
(\mathbf{m m})\end{array}$ & $\begin{array}{c}f \mathbf{1} \\
(\mathbf{G H z})\end{array}$ & $\begin{array}{c}f \mathbf{2} \\
(\mathbf{G H z})\end{array}$ & $\begin{array}{c}\boldsymbol{f 3} \\
(\mathbf{G H z})\end{array}$ & $\boldsymbol{f 2 / f 1}$ & $\boldsymbol{f 3} / \boldsymbol{f 1}$ \\
\hline 60 & 60 & 0.975 & 2.127 & 2.894 & 2.181 & 2.968 \\
\hline 65 & 55 & 0.985 & 2.116 & 2.815 & 2.148 & 2.858 \\
\hline 70 & 50 & 0.995 & 2.087 & 2.758 & 2.097 & 2.772 \\
\hline 75 & 45 & 1.005 & 2.044 & 2.728 & 2.034 & 2.714 \\
\hline 80 & 40 & 1.015 & 2.002 & 2.732 & 1.972 & 2.691 \\
\hline
\end{tabular}

Tab. 4. Comparison of resonant frequency with varying length and width, $L 3=L 4=W 3=W 4=10 \mathrm{~mm}, L 1=L 2=$ $6 \mathrm{~mm}, W 1=W 2=10 \mathrm{~mm}, S=12 \mathrm{~mm}, W \mathrm{fl}=2 \mathrm{~mm}$, $W \mathrm{f} 2=5 \mathrm{~mm}, L \mathrm{f} 1=L \mathrm{f} 2=15 \mathrm{~mm}$ and $G=0.4 \mathrm{~mm}$.

\begin{tabular}{|c|c|c|c|c|c|c|}
\hline $\begin{array}{c}\boldsymbol{W 3} \\
(\mathbf{m m})\end{array}$ & $\begin{array}{c}\boldsymbol{W 4} \\
(\mathbf{m m})\end{array}$ & $\begin{array}{c}\mathbf{f 1} \\
(\mathbf{G H z})\end{array}$ & $\begin{array}{c}\boldsymbol{f 2} \\
(\mathbf{G H z})\end{array}$ & $\begin{array}{c}\boldsymbol{f 3} \\
(\mathbf{G H z})\end{array}$ & $\boldsymbol{f 2} / \boldsymbol{f 1}$ & $\boldsymbol{f 3} / \boldsymbol{f 1}$ \\
\hline 10 & 10 & 0.975 & 2.127 & 2.894 & 2.181 & 2.968 \\
\hline 12 & 8 & 0.974 & 2.098 & 2.900 & 2.154 & 2.977 \\
\hline 14 & 6 & 0.975 & 2.060 & 2.906 & 2.112 & 2.980 \\
\hline 16 & 4 & 0.987 & 2.018 & 2.913 & 2.044 & 2.951 \\
\hline 18 & 2 & 1.000 & 1.943 & 2.916 & 1.943 & 2.916 \\
\hline
\end{tabular}

Tab. 5. Comparison of resonant frequency with varying ring width, $L=W=60 \mathrm{~mm}, L 3=L 4=10 \mathrm{~mm}, L 1=L 2=$ $6 \mathrm{~mm}, W 1=W 2=10 \mathrm{~mm}, S=12 \mathrm{~mm}, W \mathrm{fl}=2 \mathrm{~mm}$, $W \mathrm{f} 2=5 \mathrm{~mm}, L \mathrm{f} 1=L \mathrm{f} 2=15 \mathrm{~mm}$.

\begin{tabular}{|c|c|c|c|c|c|}
\hline $\begin{array}{c}\boldsymbol{L} \mathbf{1}=\mathbf{L 2} \\
(\mathbf{m m})\end{array}$ & $\begin{array}{c}\boldsymbol{f 1} \\
(\mathbf{G H z})\end{array}$ & $\begin{array}{c}\boldsymbol{f} \mathbf{G H} \\
(\mathbf{G H z})\end{array}$ & $\begin{array}{c}\boldsymbol{f 3} \\
(\mathbf{G H z})\end{array}$ & $\boldsymbol{f 2} / \boldsymbol{f 1}$ & $\boldsymbol{f 3} / \boldsymbol{f 1}$ \\
\hline 2 & 1.009 & 2.140 & 2.945 & 2.121 & 2.918 \\
\hline 4 & 0.994 & 2.096 & 2.921 & 2.108 & 2.938 \\
\hline 6 & 0.975 & 2.060 & 2.906 & 2.113 & 2.980 \\
\hline 8 & 0.962 & 2.038 & 2.900 & 2.118 & 3.014 \\
\hline 10 & 0.949 & 2.018 & 2.898 & 2.126 & 3.054 \\
\hline
\end{tabular}

Tab. 6. Comparison of resonant frequency with varying stub length, $L=W=60 \mathrm{~mm}, \quad L 3=L 4=10 \mathrm{~mm}, \quad W 3=$ $14 \mathrm{~mm}, W 4=6 \mathrm{~mm}, W 1=W 2=10 \mathrm{~mm}, S=12 \mathrm{~mm}$ $W \mathrm{f} 1=2 \mathrm{~mm}, \quad W \mathrm{f} 2=5 \mathrm{~mm}, \quad L \mathrm{f} 1=L \mathrm{f} 2=15 \mathrm{~mm}$ and $G=0.4 \mathrm{~mm}$.

\section{Results}

The antenna is fabricated on an ARLON AD 250 substrate. The dimensions are: $L=78 \mathrm{~mm}, L 1=6 \mathrm{~mm}$, $L 2=6 \mathrm{~mm}, L 3=16.5 \mathrm{~mm}, L 4=16.5 \mathrm{~mm}, L 5=11 \mathrm{~mm}$, $L 6=11 \mathrm{~mm}, L 7=11 \mathrm{~mm}, L f 1=15 \mathrm{~mm}, L f 2=15 \mathrm{~mm}$, $W=63 \mathrm{~mm}, W 1=18 \mathrm{~mm}, W 2=18 \mathrm{~mm}, W 3=21 \mathrm{~mm}$, $W 4=10 \mathrm{~mm}, W \mathrm{f} 1=2 \mathrm{~mm}, W \mathrm{f} 2=5 \mathrm{~mm}$ and $G=0.4 \mathrm{~mm}$. The fabricated antenna is shown in Fig. 6. The simulations have been done in CST Studio Suite [26].

Upon comparison of the results of the MNM analysis of the antenna with the simulated and measured results, it was found that there were some discrepancies in the resonant frequencies and the values of input impedance.

It has been reported in [27], [28] that as the values of capacitance used in the gap-coupling network are derived for asymmetric coupled microstrip line using quasi-static analysis they are inappropriate for the radiating edges of the antenna. The correction in the value of the capacitance is done in the form of a weighing factor. It has to be found out in an iterative way. In our case the value is found out to be 0.5 for the first resonance, 0.7 for the second resonance and 1.2 for the third resonance. So the weight factor of 0.5 is used up to the frequency of $1.2 \mathrm{GHz}, 0.7$ is used from 
1.2 $\mathrm{GHz}$ to $2 \mathrm{GHz}$ and 1.2 for higher frequencies. This factor is multiplied to the value of the gap capacitance.

The values of the real and imaginary part of the input impedance and $\mathrm{S}_{11}$ obtained by MNM are compared with

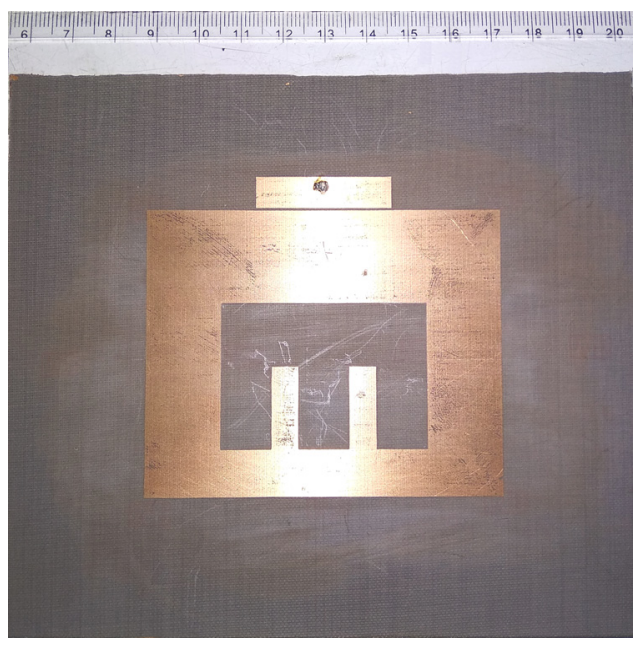

Fig. 6. Photograph of the fabricated antenna.

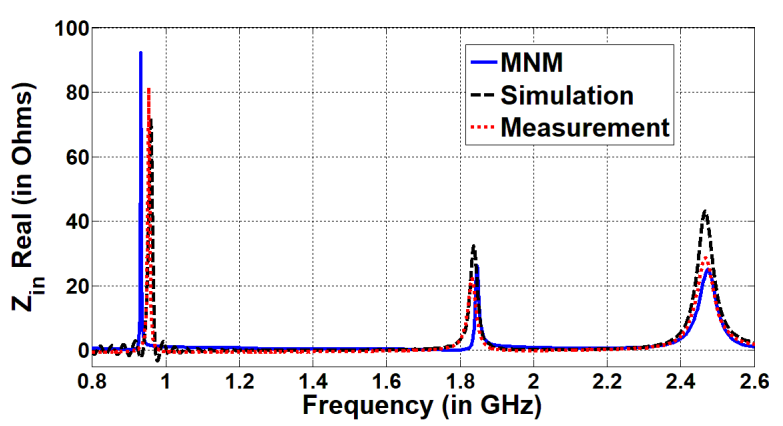

Fig. 7. Comparison of real part of input impedance.

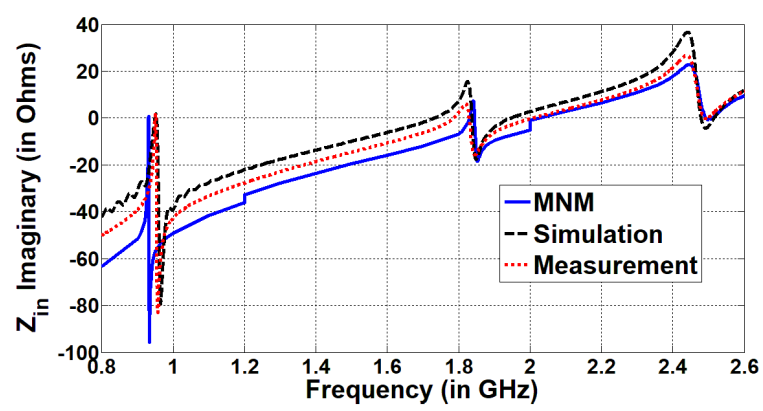

Fig. 8. Comparison of imaginary part of input impedance.

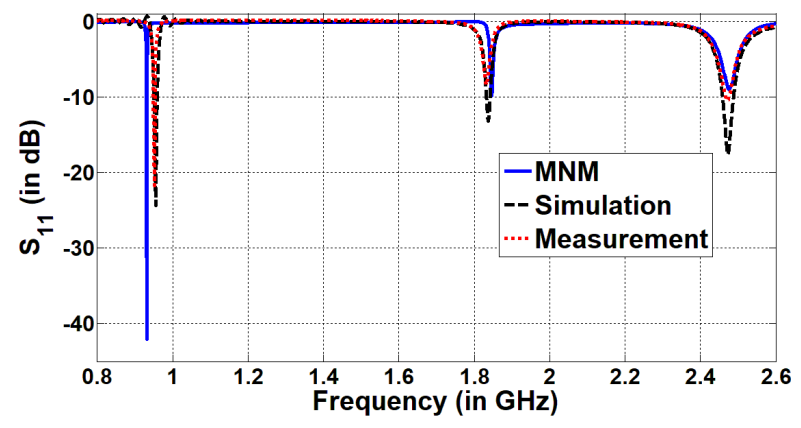

Fig. 9. Comparison of $\mathrm{S}_{11}$. the simulated and measured results and are shown in Fig. 7, Fig. 8 and Fig. 9.

The resonant frequencies obtained from the three methods are compared in Tab. 7.

It can be seen that the error in the resonant frequency obtained between MNM and measurement results is $-2.16 \%, 0.709 \%$ and $0.243 \%$ respectively at the three resonances which is within acceptable limits.

The electric field in the structure at the three resonant frequencies which is obtained using MNM is shown in Fig. 10.

Microstrip ring antenna has resonances when the path length of the ring is in multiples of guided wavelength. The

\begin{tabular}{|c|c|c|c|c|c|c|}
\hline & \multicolumn{2}{|c|}{$\mathbf{1}^{\text {st }}$ Resonance } & \multicolumn{2}{c|}{$\mathbf{2}^{\text {nd }}$ Resonance } & \multicolumn{2}{c|}{$\mathbf{3}^{\text {rd }}$ Resonance } \\
\cline { 2 - 7 } & $\begin{array}{c}\mathbf{f 1} \\
(\mathbf{G H z})\end{array}$ & $\begin{array}{c}\text { Gain } \\
(\mathbf{d B})\end{array}$ & $\begin{array}{c}\mathbf{f 2} \\
(\mathbf{G H z})\end{array}$ & $\begin{array}{c}\text { Gain } \\
(\mathbf{d B})\end{array}$ & $\begin{array}{c}\mathbf{f 3} \\
(\mathbf{G H z})\end{array}$ & $\begin{array}{c}\text { Gain } \\
(\mathbf{d B})\end{array}$ \\
\hline MNM & 0.932 & 2.208 & 1.846 & 4.363 & 2.474 & 5.34 \\
\hline Simulation & 0.9584 & 2.32 & 1.8368 & 5.5 & 2.4668 & 6.45 \\
\hline Measurement & 0.9526 & 2.883 & 1.833 & 4.67 & 2.468 & 6.07 \\
\hline
\end{tabular}

Tab. 7. Comparison of resonant frequency and gain.

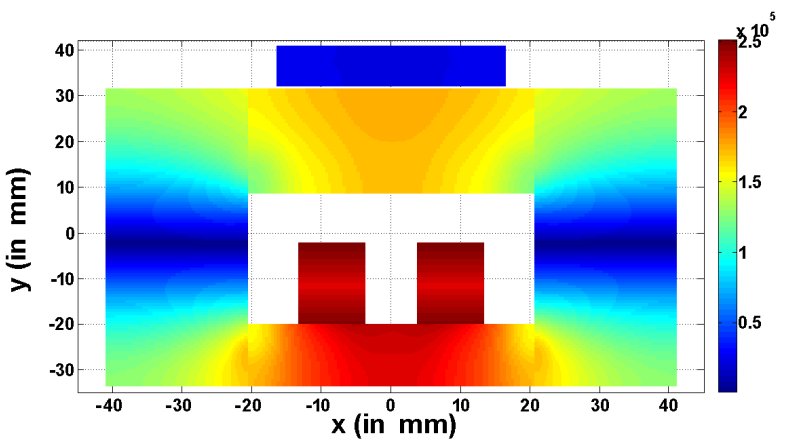

(a)

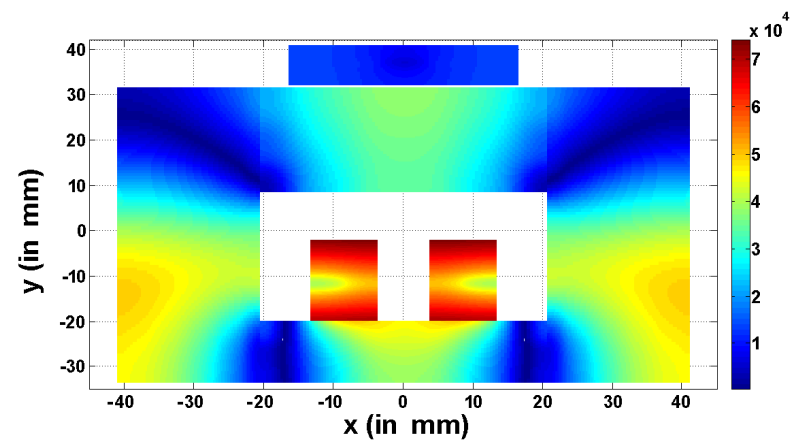

(b)

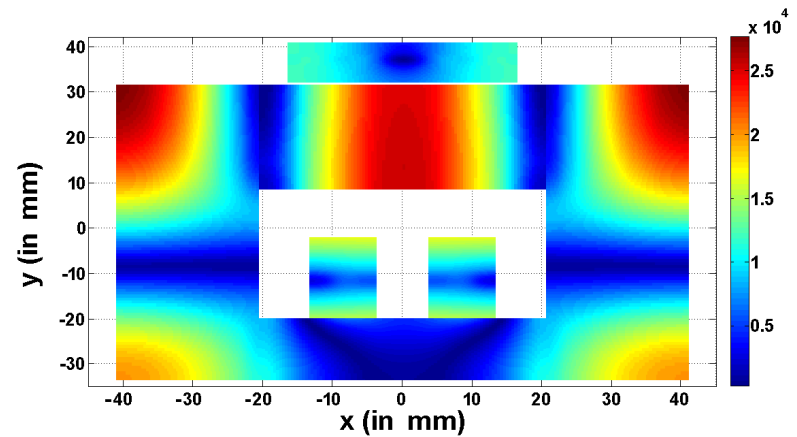

(c)

Fig. 10. Electric field magnitude at (a) $f 1$, (b) $f 2$ and (c) $f 3$. 
three resonant frequencies obtained correspond to the path length being close to $\lambda_{\mathrm{g}}, 2 \lambda_{\mathrm{g}}$ and $3 \lambda_{\mathrm{g}}$, respectively. This fact can be ascertained from the plot of electric field distribution inside the antenna as shown in Fig. 10. The surface current distributions obtained from MNM at the three resonant frequencies are plotted in Fig. 11. The stubs perturb the field and cause the shift in the positions of the maxima and minima as compared to a simple square ring antenna.

The radiation pattern has also been measured at the three frequencies and compared with the pattern obtained from MNM. The X-Z plane is the $\varphi=0^{\circ}$ plane and $\mathrm{Y}-\mathrm{Z}$ plane is the $\varphi=90^{\circ}$ plane. As cavity model analysis assumes an infinite ground plane it cannot show backside radiation. So only the normalized radiation patterns in the forward direction at the three frequencies are shown in Fig. 12, Fig. 13 and Fig. 14.

It can be seen that the antenna could produce broadside radiation at all the three resonant frequencies. Minimum value of the front to back ratio obtained is $\sim 10 \mathrm{~dB}$ and cross-polar discrimination obtained is $\sim 20 \mathrm{~dB}$ in

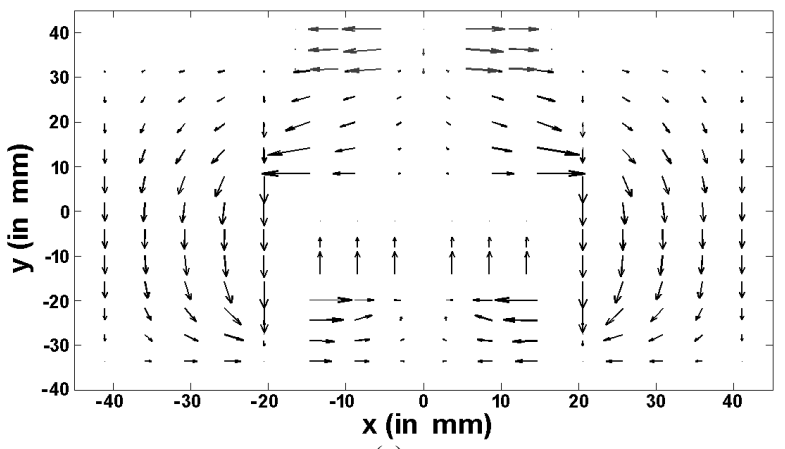

(a)

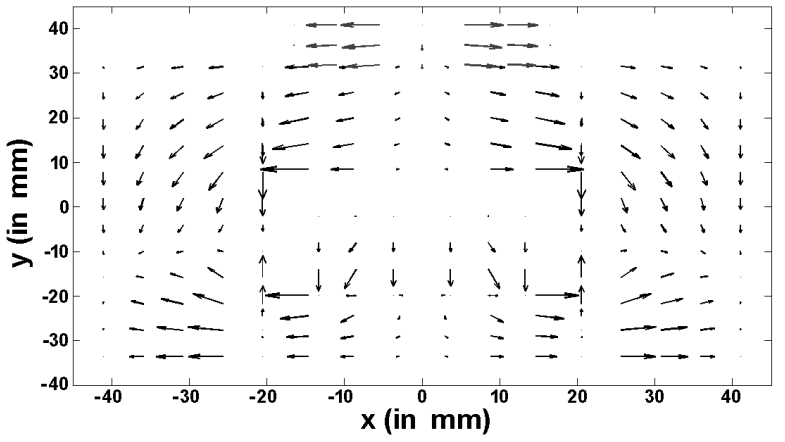

(b)

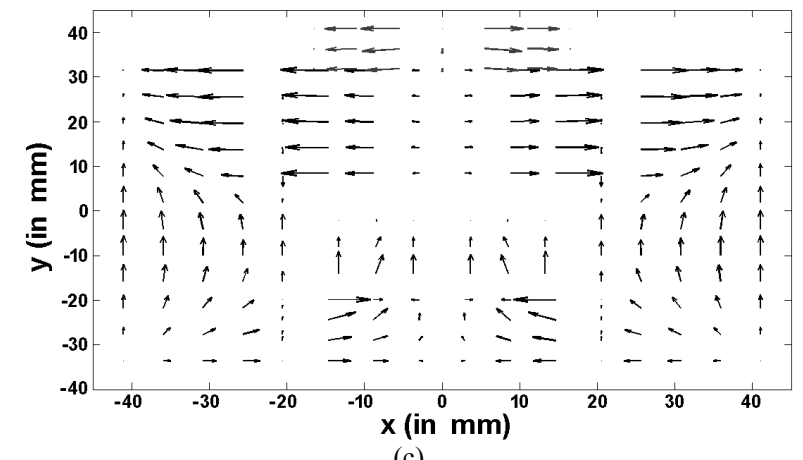

(c)

Fig. 11. Surface current density at (a) $f 1$, (b) $f 2$ and (c) $f 3$.

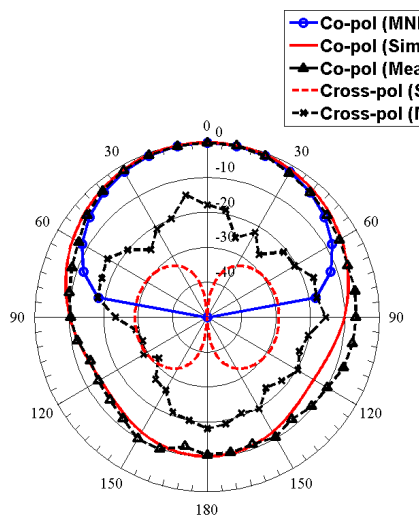

(a)

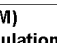

lation)

(Mimulation) (Measurement)

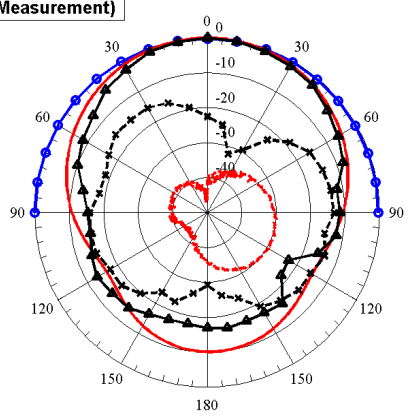

(b)
Fig. 12. Normalized radiation pattern at (a) $\varphi=0^{\circ}$ plane and (b) $\varphi=90^{\circ}$ plane in $\mathrm{dB}$ at $f 1$.

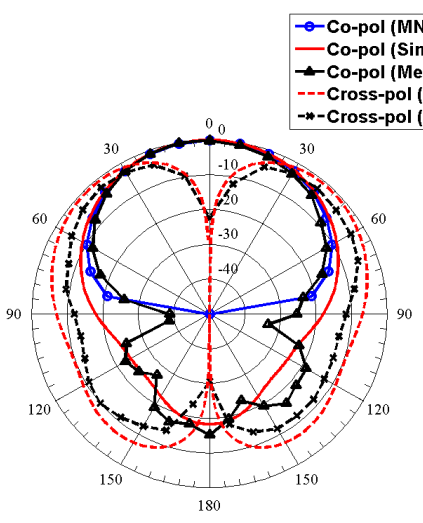

(a)
(1) (Simulation) (Measurement)

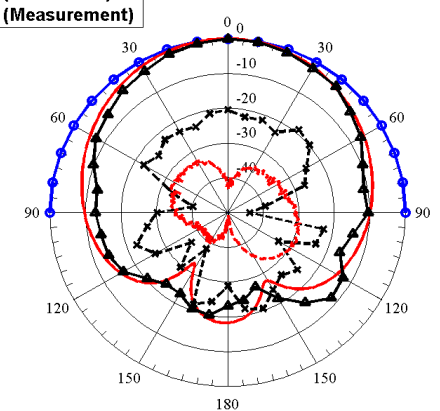

(b)
Fig. 13. Normalized radiation pattern at (a) $\varphi=0^{\circ}$ plane and (b) $\varphi=90^{\circ}$ plane in $\mathrm{dB}$ at $f 2$.

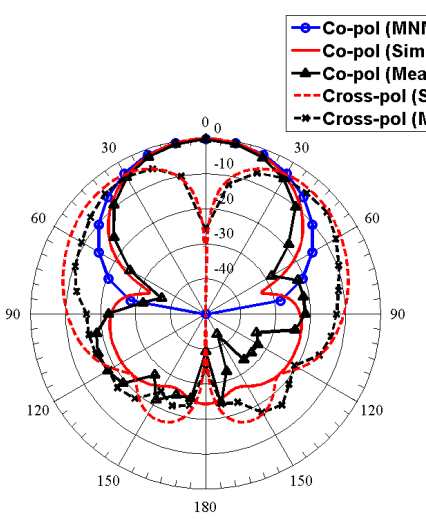

(a)

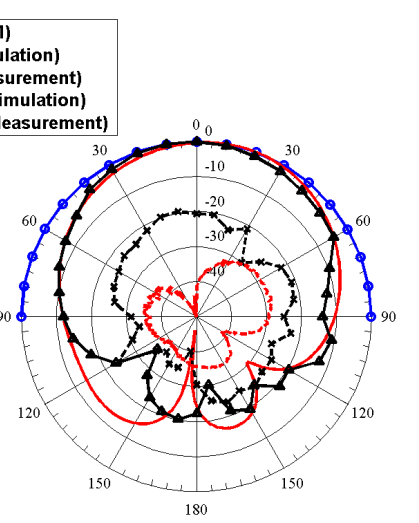

(b)
Fig. 14. Normalized radiation pattern at (a) $\varphi=0^{\circ}$ plane and (b) $\varphi=90^{\circ}$ plane in $\mathrm{dB}$ at $f 3$.

measurements. The broadside radiation can be attributed to the field perturbation in the structure as compared to a microstrip ring antenna. The performance of the proposed antenna is compared with other multiband patch antennas and summarized in Tab. 8. Reference [29] is an E-shaped patch and [30] is an 'e'-slot loaded patch antenna.

It is observed that both the E shaped antennas have a dual band response as compared to the triple band response obtained in our case. Also the proposed design is smaller compared to other patch based multiband antenna designs. 


\begin{tabular}{|c|c|c|c|c|}
\hline & $\begin{array}{c}\text { No. of } \\
\text { bands }\end{array}$ & $\begin{array}{c}\text { Frequencies } \\
(\mathbf{G H z})\end{array}$ & Size $\left(\lambda_{\mathrm{g}}\right)$ & $\begin{array}{c}\text { Shape } \\
\text { of the } \\
\text { antenna }\end{array}$ \\
\hline$[29]$ & 2 & $3.51,5.82$ & $0.469 \times 0.588$ & $\begin{array}{c}\text { E-shape } \\
\text { patch }\end{array}$ \\
\hline$[30]$ & 2 & $2.47,5.77$ & $0.613 \times 0.415$ & $\begin{array}{c}\text { e-slot } \\
\text { loaded } \\
\text { patch }\end{array}$ \\
\hline$[31]$ & 3 & $1.8,2.4,3.45$ & $0.371 \times 0.365$ & $\begin{array}{c}\text { Double U- } \\
\text { slot loaded } \\
\text { patch }\end{array}$ \\
\hline$[13]$ & 3 & $0.627,0.785,0.9$ & $0.545 \times 0.367$ & $\begin{array}{c}\text { External } \\
\text { stub } \\
\text { loaded } \\
\text { ring }\end{array}$ \\
\hline $\begin{array}{c}\text { Our } \\
\text { Work }\end{array}$ & 3 & $0.9526,1.833,2.468$ & $0.36 \times 0.32$ & \\
\hline
\end{tabular}

Tab. 8. Comparison of antenna parameters.

\section{Conclusion}

Two open circuited stubs were introduced at the inner periphery of a microstrip ring antenna so that the field perturbation at the two higher order modes would provide a broadside radiation. So the structure can be used as a triple band antenna as the fundamental mode has broadside radiation. MNM of the antenna is performed to provide a fairly accurate value of the resonant frequencies of the antenna.

\section{Acknowledgments}

The work of Suman Pradhan was supported by the Council of Scientific and Industrial Research, Government of India, File 09/096(0923) 2018 EMR-I.

\section{References}

[1] LEE, K. F., YANG, S. L. S., KISHK, A. A. Dual- and multiband U-slot patch antennas. IEEE Antennas and Wireless Propagation Letters, 2008, vol. 7, p. 645-647. DOI: 10.1109/LAWP.2008.2010342

[2] DAVIDSON, S. E., LONG, S. A., RICHARDS, W. F. Dual-band microstrip antennas with monolithic reactive loading. Electronics Letters, 1985, vol. 21, no. 20, p. 936-937. DOI: 10.1049/el: 19850662

[3] POLIVKA, M. Design of dualband quarter-wavelength patch antenna by tuning its natural resonances. In Proceedings of the IEEE Antennas and Propagation Society International Symposium. Honolulu (USA), June 2007, p. 996-999. DOI: 10.1109/APS.2007.4395664

[4] SHAFAI, L. Characteristics of printed ring microstrip antennas. In Proceedings of the Symposium on Antenna Technology and Applied Electromagnetics. Montreal (Canada), August 1996, p. 379-382. ISBN: 978-0-9692563-5-9

[5] BAFROOEI, P. M., SHAFAI, L. Characteristics of single- and double-layer microstrip square-ring antennas. IEEE Antennas and Wireless Propagation Letters, 1999, vol. 47, no. 10, p. 1633-1639. DOI: $10.1109 / 8.805910$
[6] VINOY, K. J., PAL, A. Dual-frequency characteristics of Minkowski square ring antennas. IET Microwave, Antennas and Propagation, 2010, vol. 4, no. 2, p. 219-224. DOI: 10.1049/ietmap.2008.0202

[7] WAKATSUKI, H., KIMURA, Y., HANEISHI, M. Single-layer multiband ring microstrip antennas fed by a co-planar waveguide. In Proceedings of the IEEE Antennas and Propagation Society International Symposium. Orlando (USA), July 2013, p. 926-927. DOI: 10.1109/APS.2013.6711122

[8] DESHMUKH, A. A., RAY, K. P. Broadband proximity-fed square-ring microstrip antennas. IEEE Antennas and Propagation Magazine, 2014, vol. 56, no. 2, p. 89-107. DOI: 10.1109/MAP.2014.6837068

[9] LATIF, S. I., SHAFAI, L. Microstrip square-ring antenna with capacitive feeding for multi-frequency operation. In Proceedings of the IEEE Antennas and Propagation Society International Symposium. San Diego (USA), July 2008, p. 1-4. DOI: $10.1109 /$ APS.2008.4620008

[10] PUSKELY, J., YAROVOY, A. G., ROEDERER, A. G. Two-port dual-band microstrip square ring antenna for radar applications. In Proceedings of the European Conference on Antennas and Propagations. Davos (Switzerland), April 2016, p. 1-5. DOI: 10.1109/EuCAP.2016.7481539

[11] CHEN, W. S., WU, C. K., WONG, K. L. Square-ring microstrip antenna with a cross strip for compact circular polarization operation. IEEE Transactions on Antennas and Propagation, 1999 , vol. 47 , no. 10 , p. $1566-1568$. DOI: $10.1109 / 8.805900$

[12] TONG, K. F. A new single-fed proximity coupled circularly polarized square ring antenna. In Proceedings of the Asia-Pacific Microwave Conference. Yokohama (Japan), December 2006, p. 69-72. DOI: 10.1109/APMC.2006.4429381

[13] DESHMUKH, A. A., RAY, K. P., CHINE, P. N. Multi-band stub loaded square ring microstrip antennas. In Proceedings of the Applied Electromagnetics Conference (AEMC). Kolkata (India), December 2009, p. 1-4. DOI: 10.1109/AEMC.5430706

[14] BEHERA, S., VINOY, K. J. Microstrip square ring antenna for dualband operation. Progress in Electromagnetics Research, 2009, vol. 93, p. 41-56. DOI: 10.2528/PIER09021909

[15] CHADHA, R., GUPTA, K. C. Segmentation method using impedance matrices for analysis of planar microwave circuits. IEEE Transactions on Microwave Theory and Techniques, 1981, vol. 29, no. 1, p. 71-74. DOI: 10.1109/TMTT.1981.1130292

[16] GUPTA, K. C., SHARMA, P. C. Segmentation and desegmentation techniques for analysis of planar microstrip antennas. In Proceedings of the IEEE Antennas and Propagation Society International Symposium. Los Angeles (USA), June 1981, vol. 19, p. 19-22. DOI: 10.1109/APS.1981.1148597

[17] SHARMA, P. C., GUPTA, K. C. Desegmentation method for analysis of two-dimensional microwave circuits. IEEE Transactions on Microwave Theory and Techniques, 1981, vol. 29, no. 10, p. 1094-1098. DOI: 10.1109/TMTT.1981.1130504

[18] PALANISAMY, V., GARG, R. Analysis of circularly polarized square ring and cross-strip microstrip antennas. IEEE Transactions on Antennas and Propagation, 1986, vol. 34, no. 11, p. 1340-1346. DOI: 10.1109/TAP.1986.1143766

[19] BENALLA, A., GUPTA, K. C. Multiport network model for twoport gap-coupled rectangular microstrip patches. In Proceedings of the IEEE Antennas and Propagation Society International Symposium. Ontario (Canada), June 1991, vol. 1, p. 64-67. DOI: 10.1109/APS.1991.174774

[20] BEHERA, S., VINOY, K. J. Multi-port network modeling of stub loaded microstrip ring antenna for dual-band operations. In Proceedings of the IEEE Asia Pacific Conference on Antennas and Propagation. Singapore, August 2012, p. 233-234. DOI: 10.1109/APCAP.2012.6333243 
[21] GARG, R., BHARTIA, P., BAHL, I., ITTIPIBOON, A. Microstrip Antenna Design Handbook. $1^{\text {st }}$ ed. Artech House, 2001. ISBN: 0-89006-513-6

[22] OKOSHI, T., MIYOSHI, T. The planar circuit - an approach to microwave integrated circuitry. IEEE Transactions on Microwave Theory and Techniques, 1972, vol. 20, no. 4, p. 245-252. DOI: 10.11109/TMTT.1972.1127730

[23] JAMES, J. R., HALL, P. S. Handbook of Microstrip Antennas. $2^{\text {nd }}$ ed. Peter Peregrinus Ltd., 1989. ISBN: 0-86341-150-9

[24] BEDAIR, S. S. Characteristics of some asymmetrical coupled transmission lines. IEEE Transactions on Microwave Theory and Techniques, 1984, vol. 32, no. 1, p. 108-110. DOI: 10.1109/TMTT.1984.1132620

[25] PALANISAMY, V., GARG, R. Analysis of arbitrary shaped microstrip patch antennas using segmentation technique and cavity model. IEEE Transactions on Antennas and Propagation, 1986, vol. 34 , no. 10 , p. 1208-1213. DOI: 10.1109/TAP.1986.1143737

[26] www.cst.com

[27] KUMAR, G., GUPTA, K. C. Broad-band microstrip antennas using additional resonators gap-coupled to the radiating edges. IEEE Transactions on Antennas and Propagation, 1984, vol. 32, no. 12, p. 1375-1379. DOI: 10.1109/TAP.1984.1143264

[28] KUMAR, G., GUPTA, K. C. Non radiating edges and four edges gap-coupled multiple resonator broad-band microstrip antennas. IEEE Transactions on Antennas and Propagation, 1985, vol. 33, no. 2 , p. $173-178$. DOI: 10.1109/TAP.1985.1143563
[29] HOSSAIN, M. M., WAHED, M. A., MOTIN, M. A. Design and simulation of a dual-frequency E-shaped microstrip patch antenna for wireless communication. In Proceedings of the $9^{\text {th }}$ International Forum on Strategic Technology. Cox's Bazar (Bangladesh), October 2014, p. 183-186. DOI: 10.1109/IFOST.2014.6991100

[30] ABU, M., RAHIM, M. K. A., AYOP, O. Slotted e-shape antenna design for dual frequency operation. In Proceedings of the $3^{\text {rd }}$ European Conference on Antennas and Propagation. Berlin (Germany), March 2009, p. 2416-2419. ISBN: 978-3-00-024573-2

[31] ATA, O. W., SALAMIN, M., ABUSABHA, K. Double U-slot rectangular patch antenna for multiband applications. In Proceedings of the International Symposium on Advanced Electrical and Communication Technology. Rabat (Morocco), November 2018, p. 1-6. DOI: 10.1109/ISAECT.2018.8618855

\section{About the Authors ...}

Suman PRADHAN (corresponding author) was born in August 1991. He received his M.E. from Jadavpur University in 2015. His research interests include analytical modeling of microstrip antennas.

Bhaskar GUPTA was born in March 1960. He is currently a Professor in Jadavpur University. His research interests include planar and dielectric resonator antennas and MEMS based antenna. 